\title{
Formação Docente e a Fonética e Fonologia: - Ensino da Ortografia
}

\author{
Teaching Training and the Phonetics and Phonology: \\ the Teaching of Orthography
}

Carine HAUPT*

Resumo: O presente artigo é uma discussão a respeito do ensino da ortografia, com foco nos ciclos finais do Ensino Fundamental (do $6^{\circ}$ ao $9^{\circ}$ ano). Essa discussão é pautada na análise de atividades do livro didático "Português Linguagens" (MAGALHÃES; CEREJA, 2009). Primeiramente, apresentamos uma breve exposição a respeito das características do sistema ortográfico do português brasileiro, das suas regularidades e irregularidades, para, em seguida, verificar como o livro aborda as normas ortográficas. A análise objetiva encaminhar uma reflexão sobre o trabalho e formação docente, uma vez que o professor deve ter a habilidade de avaliar as propostas dos livros didáticos. Concluímos que a preocupação com a ortografia é periférica nesses livros, nos quais o foco é o uso de algumas letras que se encontram em contextos competitivos. Em virtude disso, insistimos na necessidade de uma boa formação, na qual a disciplina de Fonética e Fonologia e seus modelos baseados no uso desempenham importante papel. Palavras-chave: Ortografia. Livro didático. Formação docente.

Abstract: This article is a discussion about the teaching of orthography in the final grades of elementary school (6th to 9th grade). This discussion is based in the analysis of activities of the textbook "Portuguese Languages " (MAGALHÃES; CEREJA, 2009). First, we present a brief statement about the characteristics of the Brazilian Portuguese orthography system, its regularities and irregularities, to then see how the book approaches the orthographic rules. The analysis aims a reflection on the teacher work and

\footnotetext{
* Doutora em Linguística pela UFSC (2011), mesma instituição em que realizou seu mestrado (2006). Professora adjunta da Universidade Federal do Tocantins, vinculada ao curso de Letras do campus de Porto Nacional. Contato: carineh@uft.edu.br.
} 
training, since the teacher must have the ability to evaluate the proposals from textbooks. We concluded that the preoccupation about the orthography is circumferential in these books, in which the focus is the use of some letters that are in competitive contexts. As a result, we insist on the need for a good training, in which the discipline of Phonetics and Phonology and their models based on usage play an important role.

Key-words: Orthography. Textbooks. Teacher training.

\section{Introdução}

Desvios em relação à norma ortográfica são comuns entre alunos de diversas faixas etárias, o que significa que o problema merece atenção também nos ciclos finais do Ensino Fundamental e não somente na fase de alfabetização, em que é comum, senão central, a preocupação com a aprendizagem das corretas correspondências entre som e letra e da norma ortográfica. Por isso, escolhemos, como objeto de estudo, material didático destinado ao $6^{\circ}, 7^{\circ}, 8^{\circ}$ e $9^{\circ}$ anos. Um levantamento feito com professores de Língua Portuguesa desses anos de escolas da rede pública do estado do Tocantins, através de um breve questionário, evidenciou que eles:

- avaliam o desempenho dos alunos em relação à ortografia como ruim;

- atribuem os problemas de ortografia a falhas na alfabetização;

- reconhecem a influência da fala na escrita;

- trabalham com treinos ortográficos, como ditados e reescrita de textos;

- entendem que devem mostrar ao aluno onde acorrem os erros.

Tendo em vista esses dados, o presente artigo tem como objetivos: i) discutir o tratamento dado pelo livro didático usado por esses professores às questões de ortografia, a fim de verificar em que medida eles podem auxiliar o professor nas atividades com esse tema; ii) refletir sobre a formação e prática docente. Trata-se de um estudo de caso, pois analisamos apenas uma obra usada em uma escola especificamente. No entanto, acreditamos que a discussão possa contribuir para um olhar sobre outros livros didáticos e fomentar reflexões acerca da formação de professores para que eles possam avaliar adequadamente as propostas desses livros. 
Antes, porém, de apresentar a análise dos livros didáticos, elaboramos uma seção com algumas considerações sobre o ensino da ortografia, tomando como base autores com diversos trabalhos na área. Após a discussão do livro didático, pretendemos tecer algumas considerações a partir da seguinte pergunta: o que fazer diante dos erros de ortografia dos alunos? Evidentemente não se trata de apresentar receitas que resolverão os problemas, mas sim de trazer reflexões a partir do que foi apresentado nas seções anteriores e, ainda, trazer à tona a Fonética e Fonologia como importante disciplina na formação dos professores de Língua Portuguesa.

\section{Algumas Considerações sobre o Ensino de Ortografia}

O ensino de língua materna é respaldado por diretrizes e parâmetros que prescrevem e orientam um ensino voltado para a construção de competências e habilidades, tendo como objeto de ensino o texto como unidade e a diversidade de gêneros textuais. Segundo os PCN de Língua Portuguesa para os $2^{\circ}$ e $3^{\circ}$ ciclos do Ensino Fundamental, "o objeto de ensino e, portanto, de aprendizagem é o conhecimento linguístico e discursivo com o qual o sujeito opera ao participar das práticas sociais mediadas pela linguagem.” (PCN, 1998, p. 22). Espera-se que o aluno seja “capaz de utilizar a língua de modo variado, para produzir diferentes efeitos de sentido e adequar o texto a diferentes situações de interlocução oral e escrita" (PCN, 1998, p. 23).

Dessa forma, não podemos mais pensar em uma escola que trabalhe a linguagem sem considerar a sua dimensão social. Uma escola que continua tendo como objeto base uma língua, ou a produção de uma língua cristalizada, apartada da língua orgânica, dinâmica e calcada em uma necessidade comunicativa real está fadada ao insucesso (KUPSKE, 2010). A escrita e, consequentemente, a ortografia, também deve ser ensinada de forma dinâmica e natural, não como um treinamento imposto. Podemos dizer que não se trata de aprender a escrever, mas sim de descobrir a escrita. Nesse sentido, o aluno deve ter espaço para elaborar as suas hipóteses acerca das normas ortográficas e o professor deve dar condições para que o aprendiz possa avaliá-las, elaborar novas hipóteses e assim, apropriar-se do sistema ortográfico da língua portuguesa. Convergem para essa perspectiva as contribuições da Fonologia de Uso (BYBEE, 2000, 2001, 2002, 2003), que não vê os processos de fala e escrita como mapeamento de uma forma 
subjacente, mas como um reflexo do uso. Assim "a jornada de escritor principiante a escritor maduro é condicionada pelo uso da linguagem escrita - em sua forma natural e de forma natural - tal qual na oralidade" (KUPSKE, 2010, p. 614).

Isso significa que expor o aluno às condições de escrita é o suficiente para que ele se aproprie das normas ortográficas? Acreditamos que a prática de leitura e de produção de diferentes gêneros textuais é importante para a aprendizagem da ortografia, no entanto, estudos têm mostrado que o ensino sistemático das normas ortográficas traz impacto positivo na sua aquisição (REGO; BUARQUE, 1997; MELO; REGO, 1998; MELO, 2002). Para discutir essa questão, temos que considerar que nosso sistema ortográfico apresenta regularidades e irregularidades, que podem ser descritas em regras. Pautaremos a explanação dessas regras em Scliar-Cabral (2003) e Morais (2007).

Scliar-Cabral (2003) divide as regras em: regras independentes do contexto; regras dependentes só do contexto fonético; regras em contextos competitivos e regras dependentes da morfossintaxe e do contexto fonético. As regras independentes de contextos englobam a correspondência biunívoca entre som (fonema) ${ }^{1}$ e grafema, ou seja, há apenas uma forma de transcrever a realização de cada fonema. É o caso das consoantes 'p', 'b', 't', 'd', 'f', 'v', 'm’ e 'n' em início de sílaba, e dos dígrafos 'nh' e 'lh'. Embora aparentemente sem complicações, há também problemas na ortografia que envolvem essas letras, como a troca entre consoantes surdas e sonoras ('p' por 'b') e dificuldades com os dígrafos, decorrentes, em alguns casos, da variedade e da fala do aluno, como, por exemplo, a escrita de 'familha' no lugar de 'família', uma vez que pode-se pronunciar [fa'mi אe].

As regras dependentes de contexto fonético são aquelas em que o uso de determinado grafema é determinado pelo contexto fonético precedente ou seguinte, ou pela posição que ocupa na palavra. É o caso do uso do fonema /k/: quando a vogal seguinte for anterior (/ e, i, $\varepsilon /$ ), usa-se o dígrafo 'qu'; quando a vogal seguinte for posterior ou central (/ a, o, u, o /), usa-se a letra 'c'. São outros exemplos o uso de 'g' e 'gu'

${ }^{1}$ A distinção entre som enquanto fone ou fonema não será feita nesse trabalho. Adotamos as nomenclaturas usadas pelos autores citados - fonema para Scliar-Cabral (2003) e som no livro didático. 
para o fonema /g/; o uso da ' $j$ ' para o fonema /3/ quando seguido de vogal anterior; o uso de ' $z$ ' para a transcrição do fonema $/ z /$ em início de palavras; o uso do ' $x$ ' para o fonema $/ \int /$ precedido de ditongos. O objetivo não é apresentar a lista completa ${ }^{2}$, mas apontar para a importância de o professor conhecer essas regras para que possa fazer um trabalho reflexivo com os alunos, muito além da memorização.

Os contextos competitivos são aqueles em que as correspondências entre fonema e grafema não podem ser explicados por regras. Esses, sim, demandam memorização. Como exemplo, podemos citar as diferentes formas de transcrever o fonema /s/: em caça, usamos 'ç'; em devassa, 'ss'; em máximo, usamos a letra 'x'; em desça, o dígrafo 'sç', etc. Observemos que o fonema / s/ encontra-se em início de sílaba e em posição intervocálica, ou seja, no mesmo contexto fonético, portanto, não temos uma regra que prevê o uso de determinada letra ou dígrafo (salvo informações lexicais, mas que também exigem memorização). Comparemos esses contextos com as regras dependentes de contexto fonético: é previsível que não se use a letra 's' em contexto intervocálico para transcrever o fonema /s/, pois ela passa a ter valor de / $\mathrm{z} /$ nesse contexto. Também é previsível que não se use a letra 'c' para o fonema /s/ quando seguido da vogal /a/, por exemplo, pois nesse contexto, a letra passa a ter valor de $/ \mathrm{k} /$.

Por fim, temos as regras dependentes da morfossintaxe e do contexto fonético. Scliar-Cabral (2003) descreve algumas regras nas quais entram em jogo tanto informações morfológicas quanto fonéticas. Restringe-se a poucos casos, como exemplo, as regras referentes ao uso de 'ão' e 'am' em verbos e substantivos e a acentuação nos oxítonos e paroxítonos terminados em / $\tilde{\mathrm{e}}_{\mathrm{I}}$ / (também, homem). Além disso, trata do uso das formas oblíquas '-no/a' e '-lo/a', do acento diferencial, do uso da crase e da mudança de vocábulo átono para tônico.

Morais (2007) nos apresenta uma divisão semelhante. Ao invés de regras, esse autor usa os termos 'regularidades' e 'irregularidades'. Estabelecendo um paralelo, temos para as regras independentes de contexto as regularidades diretas; para as regras dependentes de contexto fonético, as regularidades contextuais; para os contextos competitivos temos as irregularidades. Além disso, Morais apresenta também as regularidades

${ }^{2}$ Boa parte das regras de acentuação também é dependente do contexto fonético. 
morfossintáticas, dentre as quais inclui o uso do 'r' nas formas de infinitivo (jogar, ceder, consurir), o uso de 'u' nas flexões do pretérito perfeito do indicativo (cantou, bebeu, dirigiu), a distinção entre 'am' e ‘ão' nas formas verbais (amaram, amarão), o uso de 'd' no gerúndio (cantando) e o emprego de 'ss' nas flexões do imperfeito do subjuntivo (cantasse). Além disso, trata também de questões referentes à derivação. Observamos um tratamento diferenciado em relação às regras dependentes do contexto morfológico: enquanto Scliar-Cabral (2003) inclui nessas regras apenas aquelas que também têm dependência de contexto fonético, Morais (2007) abarca também contextos fonéticos competitivos, como, por exemplo, o uso de 'ss' no imperfeito do subjuntivo. Disso resulta uma lista maior de regularidades morfossintáticas.

Conhecer essas características do sistema ortográfico do português brasileiro, de suas regularidades e irregularidades, é fundamental para o professor de língua. Além disso, é também fundamental que o professor conheça as diferentes variedades e os diversos falares de seus alunos. Consideramos que debruçar-se sobre essas variedades é o primeiro passo para se fazer um bom trabalho com a ortografia. Nessa perspectiva, o professor poderá entender o que há por trás dos desvios ortográficos de seus alunos decorrentes das transcrições da fala e de analogias que resultam em casos de hipercorreção, por exemplo.

Diante dessa exposição, podemos voltar à questão supracitada: é necessário trabalhar a ortografia sistematicamente? Se sim, como fazê-lo? Vimos que os contextos competitivos ou as irregularidades demandam memorização. Nesse caso, podemos supor que a exposição às atividades de leitura e escrita são cruciais, sem que haja a necessidade de propor listas de palavras isoladas para a memorização ou outras atividades específicas de ortografia. Para as regularidades ou as regras dependentes de contexto, seja ele fonético ou morfossintático, acreditamos que tornar as regras conscientes para os alunos só tem a contribuir para a apropriação do sistema ortográfico. Todavia, não descartamos, para essas regularidades, a importância da exposição, pois a partir do uso, do input ao qual o aluno é exposto, emergem generalizações que podem dar conta das regras dependentes de contexto.

É com esse olhar que passaremos agora para a análise dos livros didáticos. Pretendemos verificar se as regularidades e irregularidades são abordadas nos livros e como são apresentadas aos alunos. Também verificaremos se os livros didáticos apresentam conteúdos referentes à fonética e fonologia para, em seguida, discutir acerca das contribuições que essas disciplinas podem dar para o ensino da ortografia. 


\section{A Ortografia no Livro Didático "Português Linguagens"}

Os livros analisados são da coletânea "Português Linguagens" (CEREJA; MAGALHÃES, 2009). São quatro livros destinados aos ciclos finais do Ensino Fundamental $\left(6^{\circ}\right.$ ao $9^{\circ}$ ano), aprovados pelo Programa Nacional do Livro Didático (PNLD - MEC, 2008). Com base na exposição da seção anterior, a análise das atividades desses livros será pautada nos seguintes questionamentos:

1) O manual do professor oferece orientações para o trabalho com a ortografia?

2) Que atividades são propostas para ensinar ortografia?

3) O livro didático trata diferentemente os casos irregulares e os casos regulares da norma ortográfica?

4) Que correspondências entre letra e som o livro didático propõe que se ensine?

No Quadro 1, fizemos um levantamento de todas as atividades sobre ortografia, distribuídas por ano. Incluímos também os conteúdos referentes à fonética e à fonologia apresentados aos alunos. Um rápido olhar sobre o quadro evidencia que, no $6^{\circ}$ ano, há uma preocupação em introduzir aspectos teóricos sobre a língua e conceitos que serão importantes para os demais anos. Nos anos subsequentes, percebemos preocupações mais pontuais, especialmente referentes às irregularidades, isto é, aos contextos competitivos, como, por exemplo, ao uso da letra 's'; e ao emprego adequado de palavras com escrita muito semelhante, algumas homófonas. Fica evidente, ainda, que o foco é o emprego de determinada letra e não a transcrição de determinado som/fonema. 
Quadro 1 - Conteúdos referentes à fonética/fonologia e à ortografia no livro didático "Português Linguagens" (CEREJA; MAGALHÃES, 2009)

\begin{tabular}{|c|c|}
\hline \multirow{8}{*}{$6^{\circ}$ ano } & Fonema e letra \\
\hline & Emprego da letra 'h' \\
\hline & Dígrafo e encontro consonantal \\
\hline & Encontros vocálicos \\
\hline & Divisão silábica \\
\hline & Sílaba átona e tônica \\
\hline & Acentuação das oxítonas e proparoxítonas \\
\hline & Acentuação das paroxítonas \\
\hline \multirow{5}{*}{$7^{\circ}$ ano } & 'j’ ou 'g' (parte I) \\
\hline & 'j' ou 'g' (parte II) \\
\hline & há ou a \\
\hline & mal ou mau \\
\hline & mas ou mais \\
\hline \multirow{6}{*}{$8^{\circ}$ ano } & Emprego da letra 's' (parte I) \\
\hline & Emprego da letra 's' (parte II) \\
\hline & Emprego da letra ' $z$ ' \\
\hline & 'x' ou 'ch' \\
\hline & Emprego da palavra porque (parte I) \\
\hline & Emprego da palavra porque (parte II) \\
\hline \multirow{3}{*}{$9^{\circ}$ ano } & Tem ou têm? vem ou vêm? \\
\hline & 'c', 'ç' ou 'ss' \\
\hline & 'e' ou 'i'? 'o' ou 'u'? \\
\hline
\end{tabular}

\subsection{O manual do professor oferece orientações para o trabalho com a ortografia?}

Há dois momentos, no manual do professor, em que se faz alguma remissão ao ensino de ortografia. O primeiro momento é quando os autores apresentam as seções que compõem cada capítulo do livro didático. A seção 
que trata dos conteúdos listados no Quadro 1 tem o título "De olho na escrita". Fazem parte dessa seção ainda outros conteúdos gramaticais, de natureza morfológica e sintática, que não são o foco do presente trabalho. A descrição para essa seção é a seguinte:

Nesta seção, os problemas notacionais da língua - ortografia e acentuação, por exemplo - recebem uma atenção especial, com trabalho contínuo e sistematizado. Em dois ou mais capítulos de cada unidade didática, o aluno desenvolve, pelo método indutivo, uma atividade relacionada ao assunto, inferindo as regras a partir das recorrências e pondo-as em prática. (MAGALHÃES; CEREJA, 2009).

Observamos, pela descrição, pontos positivos em relação à proposta. Chama-nos especial atenção a menção ao método indutivo, ou seja, a proposta é que o aluno, observando e analisando o uso de determina letra, por exemplo, possa inferir a regra de seu uso. É um método pertinente para depreender as regularidades das normas ortográficas, embora o mesmo não seja possível para as irregularidades. Acreditamos que a proposta é condizente com um ensino atualizado de língua, uma vez que o aluno assume posição ativa ao observar e elaborar hipóteses acerca da normatização ortográfica. Verificaremos, em seguida, a partir da análise de algumas atividades, se a descrição apresentada no manual confere com a abordagem apresentada aos alunos.

A outra passagem do manual do professor que trata do ensino da ortografia está na seção de sugestões de estratégias para o professor. Para a seção 'De olho na escrita', as estratégias propostas são a resolução dos exercícios oferecidos pelo livro individualmente ou em pequenos grupos. Além disso, há também a sugestão de fazer uso de jornais e revistas para recolher exemplos que ilustrem o tópico que está sendo estudado e de expor esses exemplos reunidos em cartazes. Não há nenhum encaminhamento específico para o trabalho com a ortografia. Não há menção alguma sobre as regularidades e irregularidades da norma ortográfica ou sobre a correspondência de letra e som/fonema, por exemplo. São, portanto, poucas as orientações que o manual oferece ao professor para trabalhar a ortografia. Além do manual em si, há as respostas às atividades propostas nas unidades, com observações esporádicas em relação às variedades linguísticas. Passemos, 
então, a mostrar algumas atividades para responder aos demais questionamentos.

\subsection{Que atividades são propostas para ensinar ortografia?}

Primeiramente, trazemos a abordagem feita ao conteúdo 'Fonema e letra'. Há a introdução do assunto com um pequeno texto (essa é uma prática constante em todos os conteúdos). Em seguida, compara-se o número de letras com o de sons das palavras posso e dedos. Depois, apresenta-se a representação fonológica das palavras vem e quem, para, finalmente, apresentar a definição de fonema e de letra. Após vêm os exercícios, cujo foco é evidenciar que a relação entre letra e som nem sempre é biunívoca, como evidenciam os exemplos abaixo:

(1) Nas palavras choque, chuvoso, xadrez, enxaguar, que letras representam o fonema $/ \mathrm{S} /$ ?

Leia as palavras: fixo, pretexto, xampu, tóxico, mexerica, exótico, inexperiência, exibir. Em quais delas a letra $\mathbf{x}$ corresponde:

a) ao fonema $/ \mathrm{J} /$ ("chê")?

b) aos fonemas $/ \mathrm{ks} /$ ?

c) ao fonema $/ s /$ ("sê")?

d) ao fonema / z/ ("zê")?

Notamos que há uma preocupação em fazer com que o aluno observe alguns dados para tirar suas próprias conclusões, conferindo, assim, um caráter indutivo. A pertinência de se ensinar conceitos como fonema não será discutida neste trabalho. Queremos evidenciar como ponto positivo o fato de mostrar ao aluno que nem sempre há uma relação biunívoca entre som e letra, uma vez que isto se constitui de um conhecimento útil para compreender algumas regularidades contextuais, como as referentes ao uso de alguns dígrafos, conceito trabalhado em unidade subsequente. Consideramos problemática a transcrição fonológica de palavras como vem $(/ \mathrm{vẽy} /)$ e quem $(/ \mathrm{kẽy} /)^{3}$, sem maiores detalhes sobre a particularidade da

\footnotetext{
${ }^{3}$ Os exemplos são especialmente complexos, tendo em vista que envolvem ampla discussão acerca das vogais nasais, para a qual existem diferentes posições (MATTOSO JR., 1979; WETZELS, 1988, 1997 apud BATISTI; VIEIRA, 2005).
} 
ditongação que não é marcada na escrita. Diante disso, salientamos que o professor precisa de uma boa bagagem de conhecimento de fonética e fonologia para dar conta dessa exposição. Reforçamos, aqui, a importância dessa disciplina nos cursos de licenciatura.

Essa abordagem de caráter indutivo observada no conteúdo "Fonema e letra" não é uma constante nas atividades sobre ortografia. Pelo contrário, quando se trata de discutir o uso de determinadas letras, as regras são simplesmente apresentadas e os exercícios remetem para a repetição, para o uso sem reflexão a partir de 'faça como no modelo', como podemos verificar nos excertos 2 (explanação do conteúdo) e 3 (exercício) referentes ao uso da letra 's'.

(2) Assim, conforme você observou, emprega-se a letra s:

- quando a palavra é formada com sufixos -oso, -osa, que indicam qualidade em abundância, intensidade: atenciosa - cheiroso - charmosa - furiosa

- nas formas verbais dos verbos pôr e querer e seus derivados: puser - quiser supusermos-quisermos

Também se emprega a letra $\boldsymbol{s}$ :

- nos sufixos -ês, -esa, que indicam origem, naturalidade: tailandês - tailandesa japonês-japonesa

- no sufixo-ense, que indica origem, naturalidade: amapaense-espirito-santense.

(3) Faça como no exemplo:

Este almoço está uma delícia.

Este almoço está delicioso.

a) Não gosto de pessoas cheias de rancor.

b) É uma joia de muito valor.

c) A aluna é cheia de atenção e capricho.

d) A personagem do filme é cheia de mistério.

É salutar observarmos que os autores fazem uma introdução interessante sobre o uso da letra 's', induzindo o aluno a concluir que som /s/ pode ser transcrito por várias letras e dígrafos e que o som /z/ pode ser transcrito pelas letras 's' e ' $z$ '. No entanto, ao apresentarem as regras (excerto 2), desviam o foco para questões morfológicas. Não se discute mais o som que a letra ' $\mathrm{s}$ ' pode representar, tanto que são apresentados exemplos em que o 's' transcreve o fonema / z/ - tailandesa - e o fonema 
/s / - amapaense. Assim, a distinção feita na introdução acaba sendo acessória, uma vez que o foco passa a ser o uso de alguns sufixos.

A discussão sobre o uso da letra 's' se estende por mais uma unidade. $\mathrm{Na}$ sequência, mesclam-se regras morfológicas (adjetivos derivados de substantivos; derivação de palavras) com regras dependentes de contexto fonético ('s' após ditongos). Transcrevemos abaixo um exercício dessa unidade. A ideia de propor ao aluno justificar a sua resposta é interessante, pois pressupõe reflexão, no entanto, consideramos o exercício bastante óbvio, pois todas as palavras que estão grafadas com ' $z$ ' estão em desacordo com a norma ortográfica. Logo, não se impõe grande desafio ao aluno.

(4) Identifique entre as palavras a seguir as que estão grafadas em desacordo com as regras ortográficas vistas. Justifique sua resposta.

virose - defesa - canza - invés - atrazado - atrás - tesoura - tezouro - náusea gostoso - vaidoso - aviso - diversão - pouso.

O excerto 5 é parte do trabalho proposto sob o título 'o uso da letra ' $z$ ". Observamos uma proposta que encaminha o aluno a deduzir a regra, que depende da classificação morfológica da palavra e da sua origem. No entanto, logo após as perguntas e a dedução da regra, volta-se à abordagem tradicional, incluindo novas regras em que se usa a letra ' $z$ '. Embora haja alguns momentos em que se busque a construção do conhecimento a partir da observação, há predominantemente a exposição de regras de forma acabada para o aluno.

(5) a) A que classe gramatical pertencem as palavras esperto, certo, pobre, belo, árido e pálido?

b) Os substantivos esperteza, certeza, pobreza, beleza, aridez e palidez são concretos ou abstratos?

c) Deduza a regra: Em que tipo de palavra são empregados os sufixos -ez e -eza?

Veja outros casos do emprego da letra $z$ :

- em verbos derivados de palavras que não contém $-\boldsymbol{s}$ na silaba final + -izar: frágil + izar = fragilizar - civil + izar = civilizar.

- em palavras derivadas de outras que não contêm $-\boldsymbol{s}$ na sílaba final + -zinho ou -zinha: pai + zinho $=$ paizinho $-i r m a \tilde{a}+$ zinha $=$ irmãzinha 


\subsection{O livro didático trata diferentemente os casos irregulares e os casos regulares da norma ortográfica?}

A distinção entre as regularidades e irregularidades na norma ortográfica não é discutida nesse livro didático. $\mathrm{O}$ trabalho proposto com as letras ' $x$ ' e 'ch' evidenciam isso. $\mathrm{Na}$ exposição, apresentam-se regras (contextos fonéticos previsíveis para o uso do ' $x$ ' e para o uso do dígrafo). Nos exercícios, conforme podemos ver no excerto 6, são incluídas palavras em que o uso dessas letras não é previsível ao lado de palavras em que o emprego da letra ' $x$ ' é contextualmente regular (' $x$ ' depois de ditongos e depois de 'en'). São irregularidades, como é o caso das palavras cachimbo, xingar e puxar. Essa mistura é recorrente em outros exercícios, como, por exemplo, no apresentado no excerto 7, que trata do uso das vogais 'e' e 'i'. Observemos que, na palavra quase, o uso da letra 'e', mesmo sendo pronunciada como 'i', é previsível pelo contexto fonético de sílaba átona final, enquanto todas as outras palavras se constituem de casos de irregularidades, que exigirão do aluno a memorização da forma ortográfica.

(6) Na sequência de palavras abaixo, todos estão corretamente grafadas, exceto uma. Reescreva-a em seu caderno com a grafia apropriada.

cachimbo - xingar - puchar - enxurrada - enxame - trouxa.

(7) Nos pares de palavras a seguir, qual é a forma adequada, de acordo com a variedade padrão? Escreva-a em seu caderno.

a) empecilho ou impecilho?

b) quase ou quasi?

c) senão ou sinão?

d) previlégio ou privilégio?

e) siquer ou sequer?

f) penicilina ou pinicilina?

g) criação ou creação?

Ao retomar as atividades referentes ao uso das letras 's' e ' $z$ ', vemos que os casos dos sufixos -oso e ---eza, por exemplo, constituem-se de contextos competitivos, pois estão no mesmo contexto fonético (intervocálico) e há duas representações para o mesmo fonema. Podem, portanto, ser considerados como irregularidades da norma ortográfica, 
mesmo que haja dependência de contexto morfológico, conforme ScliarCabral (2003). O que se observa é que os autores optaram, provavelmente como tentativa de diminuir a incidência de erros envolvendo essas letras, explorar essas regularidades morfológicas, mais especificamente de derivação. Não se observa um tratamento voltado para a discussão das regularidades e irregularidades em nível fonético, que poderia ser feito ao tratar-se, por exemplo, do uso de 's' e 'ss' para transcrever o som /s/. Ao invés de explicar o uso dessas letras em duas seções distintas, poder-se-ia abordá-las em uma mesma seção, a fim de discutir as regularidades e irregularidades.

A proposta de trabalho desse livro didático com as letras ' $s$ ' e ' $z$ ' mostra que o foco são as regularidades morfossintáticas, sem distinção entre regras que também dependem de contexto fonético e as regras que se encontram em contexto fonético competitivo (com exceção do uso do ' $x$ ' e do 'ch', para o qual são apresentadas regras dependentes de contexto fonético). Isso exige do aluno a memorização de diversas regras, conclusão que podemos tirar a partir das listas de exercícios de completar, de reescrever corretamente e de seguir o modelo. A quantidade de regras dependentes do contexto morfológico, portanto, acaba sendo bastante grande. A proposta de trabalho com as letras 'c', 'ç' e 'ss', no $9^{\circ}$ ano, reforça essa conclusão ao apresentar uma extensa lista de regras, algumas para dar conta de um número reduzido de palavras, como, por exemplo, a derivação de intercessão da palavra interceder (regra ced-cess).

As regras dependentes de contexto morfossintáticos e de derivação são pertinentes, no entanto, o que questionamos é a sua quantidade e a maneira como são apresentadas. Na forma de lista, elas acabam remetendo para a memorização. Nesse caso, seria mais pertinente considerar o emprego dessas letras como irregularidades da norma ortográfica, já que temos contextos competitivos, e esperar que o aluno, a partir do contato com a escrita, passe a memorizar aquelas que são mais frequentes no seu cotidiano. As regras dependentes do contexto morfológico podem auxiliar quando se trata de casos que abrangem muitas palavras, como o uso de 'ss' na conjugação verbal do subjuntivo (ex. comprasse). Consideramos pertinente, então, avaliar a produtividade dessas regras de cunho morfossintático para não sobrecarregar o aluno. 


\subsection{Que correspondências entre letra e som o livro didático propõe que se ensine?}

As correspondências entre som e letra são discutidas em alguns momentos no decorrer dos quatro livros. No $7^{\circ}$ ano, ao estudar o uso das letras 'j' e 'g', na parte I, são feitas perguntas sobre os valores dessas letras, que dependem da vogal que as segue (valor do $/ \mathrm{g} /$ ou $/ \mathrm{Z} /$ ). No $8^{\circ}$ ano, explora-se as formas de escrever o fonema /s/. Em ambos os casos, são feitas aos alunos apenas perguntas sobre a correspondência entre som e letra na parte introdutória da seção e, depois, passa-se para uma abordagem morfossintática. Como exemplo, temos a introdução do estudo da letra 's'. Após as perguntas listadas no excerto 7 , apresentam-se as regras dos usos dos sufixos, conforme apresentadas no excerto 2. Além disso, trata-se de exercícios que remetem para a mera identificação.

\section{(7) 1. Identifique no poema palavras que apresentam o som / s/ ("sê")?}

2. Em qual(is) dessas palavras o som / s/ ("sê") é representado, na escrita, pela letra:
a) $s ?$
c) $c / c ?$
b) $x$ ?
d) $s s ?$

Ao tratar do uso das vogais 'e' e 'i', 'o' e 'u', no $9^{\circ}$ ano, há uma apresentação pertinente sobre a correspondência entre letra e som, remetendo para a oralidade. Nesse momento, é esclarecido ao aluno que nem sempre o que produzimos na fala é representado na escrita, e coloca-se como exemplo o uso das vogais 'e' e 'o' em contextos átonos, que normalmente são pronunciados como 'i' e 'u'. Em seguida, listam-se regras que envolvem determinadas sufixos e formas verbais para o emprego de 'e', 'i', 'o' e 'u'. Apenas para a letra 'o' há uma regra que retoma a exposição anterior: “usase a letra $\boldsymbol{o}$ no final de palavras, quando forem átonas: leio, mito, foto." Ignora-se, por exemplo, que a mesma regra se aplicaria também para o uso da letra 'e'.

É importante esclarecer que não se trata de desmerecer as regras de orientação morfossintática. Trata-se de avaliar a pertinência, por exemplo, de uma regra como "emprega-se o 'e' nas formas dos verbos terminados em -oar/-uar." Sabemos que os alunos apresentam muitos erros decorrentes de transcrição de fala. E, ao introduzir o conteúdo referente ao uso das vogais ' $e$ ', 'i, 'o' e 'u', o próprio livro didático menciona que não há uma correspondência entre o que falamos e escrevemos. Então, não seria mais pertinente discutir essa relação entre fala e escrita com os alunos, apresentando 
os casos previsíveis por regras de contexto fonético para explorar as correspondências entre letra e som?

\section{Reflexões para o Ensino da Ortografia e Formação Docente}

A análise das atividades sobre ortografia do livro didático "Português Linguagens" evidenciou, primeiramente, que elas são em pequeno número do $6^{\circ}$ ao $9^{\circ}$ ano. Depois, evidenciou que o foco são regras dependentes de contexto morfológico, não sendo as regras dependentes de contexto fonético uma preocupação, talvez por pressupor-se que o aluno já tenha adquirido esse conhecimento nas séries iniciais do Ensino Fundamental. Identificamos, assim, que não há discriminação entre os casos regulares e irregulares da nossa ortografia, uma vez que essa distinção não é apresentada em detrimento da lista de contextos morfológicos do uso das letras discutidas. A falta dessa distinção se evidencia quando nos exercícios são apresentados casos de irregularidades juntamente com os exercícios das regras estudadas. Em raros momentos, menciona-se uma regra de cunho fonético (uso de ' $\mathrm{x}$ ' depois de ditongo; uso do 'e' em final átono; uso do 's' depois de ditongo). Por fim, podemos concluir também que a correspondência entre som e letra é tema acessório, configurando-se de questionários introdutórios para o estudo do uso de determinada letra que se encerram em listas de regras de derivação, em grande parte.

É esse o material que o professor tem como apoio para as suas aulas. Tendo-o como base ${ }^{4}$, voltamos à pergunta inicial, lançada na introdução deste texto: o que fazer diante dos problemas de ortografia dos alunos? A resposta já é de senso comum, mas merece ser repetida: o livro didático, qualquer que seja ele, não é o suficiente para sanar as dificuldades ortográficas dos alunos. Cabe ao professor identificar quais são essas dificuldades e tomar suas decisões diante desses problemas. Nesse sentido, os livros didáticos devem ser avaliados com muita cautela, para que não se tornem um guia inapropriado para as atividades referentes à norma ortográfica. As atividades analisadas neste texto evidenciam uma abordagem voltada para a repetição e memorização, que não consideramos pertinente para o trabalho com a ortografia, nem com a língua, de forma geral, uma vez que não pressupõe a construção do conhecimento.

${ }^{4}$ Não é objetivo deste trabalho classificar o livro como bom ou ruim. 
Então, além de conhecer as dificuldades ortográficas de seus alunos e a variedade dialetal dos mesmos, cabe ao professor planejar o seu trabalho, tendo o proposto nos livros didáticos apenas como apoio, sem medo de descartar o que não converge para um ensino dinâmico da língua. Para um ensino dinâmico da ortografia, propomos um trabalho reflexivo, a exemplo de alguns questionamentos feitos na obra analisada. No entanto, essa metodologia deve ser uma constante e não apenas parte introdutória. Para que o professor tenha sucesso nessa mediação do conhecimento sobre a norma ortográfica, é fundamental que ele mesmo a conheça, saiba classificar os erros dos alunos como decorrentes de transcrição de fala, ou de falta de conhecimento de alguma regra dependente de contexto, fonético e/ou morfológico, ou de confusão gerada por contexto competitivo. Sem esse conhecimento, o professor corre o risco de ficar perplexo diante dos erros ortográficos e sem ação.

É interessante que o professor entenda que a maioria dos erros ortográficos apresenta uma lógica. Ou seja, o aluno, ao escolher determinada letra para representar um fonema, pauta-se ou nas regras que já domina, ou na ortografia das palavras que já conhece, ou na transcrição da fala. Decorrem disso, por exemplo, erros baseados em analogias, como a escrita de saldade ao invés de saudade, uma vez que, em muitas palavras, escreve-se 'l', mas pronuncia-se 'u'. Explorar a lógica que os alunos usaram para suas escolhas ortográficas é outro caminho para trabalhar de forma reflexiva os problemas de ortografia. Nesse sentido, o livro didático analisado pouco, ou nada, tem a contribuir. Além do trabalho reflexivo, frisamos novamente a importância de atividades diversificadas de leitura e produção como forma de expor o aluno ao máximo de experiências com o mundo letrado. A partir desse contato, o aluno pode memorizar a escrita de palavras com irregularidades e até depreender, pelo uso, regras dependentes de contexto.

Constatamos, a partir do questionário realizado com os professores, que eles trabalham com treinos ortográficos, como ditados e reescrita de textos, e que sentem a necessidade de mostrar ao aluno onde ocorrem os erros. A abordagem feita pelo livro didático reforça essa prática, uma vez que propõe exercícios em que o aluno precisa completar lacunas e seguir o modelo, além de apresentar listas de regras para os alunos. Não se trata de punir esse tipo de atividades, mas sim de questionar a pertinência delas como forma de promover a aprendizagem do aluno. Consideramos que ditados, por exemplo, podem ser muito úteis para fins de diagnóstico. Atividades de reescrita podem ser muito construtivas, desde que o aluno saiba por que 
errou, isto é, não basta apresentar a ortografia correta de determinada palavra, mas levar o aluno a refletir sobre a sua escolha e sobre a forma correta.

Essa discussão nos leva, inevitavelmente, para a questão da formação docente, tanto em relação ao domínio da língua quanto das metodologias de ensino. Em relação à ortografia, acreditamos que uma boa formação em Fonética e Fonologia seja crucial. O professor precisa conhecer o sistema vocálico e consonantal do português brasileiro, precisa compreender como se dá a correspondência entre sons e fonemas, sem perder de vista as variedades. Propomos, ainda, ir além das teorias tradicionais, como o estruturalismo e o gerativismo, a partir dos quais se discutem pares míninos, alofonia, traços distintivos, dentre outros conceitos. Sugerimos, já no início deste artigo, as contribuições da Fonologia de Uso. Trata-se de uma abordagem que diverge de abordagens tradicionais, dentre outras razões, por não compartilhar a ideia de forma subjacente, uma vez que o uso determina as representações mentais. Isso significa dizer que as representações não são fixas ${ }^{5}$, pois mudam de acordo com as experiências de cada falante com a língua. Entender que o uso determina a gramática de uma língua direciona-nos para outro olhar sobre o ensino da língua, não mais como produto acabado.

O modelo fonológico de Bybee (2001) - a Fonologia de Uso oferece uma proposta alternativa de análise linguística, e, ainda segundo a autora, embora tal modelo assuma princípios gerais do conexionismo, um ponto crucial que distancia o conexionismo deste é o caráter inerentemente social da linguagem, pois, para esse modelo, a gramática emerge do uso apenas. Uso que também é característica cerne do paradigma sociointeracionista. (KUPSKE, 2010, p. 610).

Outra vantagem desse modelo teórico consiste no seu caráter cognitivo. Todas as experiências do falante são categorizadas, da mesma

${ }^{5}$ A experiência afeta a representação, isto é, palavras e construções mais frequentes são mais fortes no sentido de que são mais facilmente acessadas, enquanto as menos frequentes tornam-se mais fracas, podendo até ser esquecidas. A força lexical de uma palavra pode mudar à medida que é mais ou menos usada em diferentes contextos. Essa é a principal diferença entre as abordagens modulares em que as representações, regras ou restrições são estáticas e todas as regras ou representações do mesmo componente têm o mesmo status. 
forma como outros objetos que não linguísticos também o são. Assim, as generalizações emergem dessas categorizações, ou seja, as regras resultam das representações armazenadas que resultam do uso. Ao aprendermos a escrita, categorizamos os dados escritos aos quais temos acesso, e fazemos generalizações a partir das redes resultantes das categorizações, por exemplo, generalizamos a escrita de /ãw/ como ‘ão' quando tônico e 'am' quando átono. Muitas vezes, a escrita de /ãw/ é apresentada pelo professor ao aluno como regra, como produto acabado. O aluno não seria capaz de, através do input do léxico escrito generalizar, considerando as similaridades fonéticas das diferentes categorias? Nesse sentido, é possível discutir a aprendizagem da escrita/ortografia a partir de uma abordagem de fonologia baseada no uso.

\section{Conclusão}

Para encerrar esta discussão, reunimos alguns pontos que consideramos essenciais neste trabalho: i) a preocupação com o ensino da norma ortográfica não deve ser restrita à alfabetização, uma vez que muitos problemas persistem nas séries seguintes. Deve, portanto, ser objeto de atenção do professor; ii) os livros didáticos devem ser analisados com critérios, considerando a metodologia pressuposta a partir das atividades sobre a ortografia, a distinção de normas dependentes de contexto e as irregularidades e as correspondências entre letra e som; iii) o trabalho sistemático com a ortografia, especialmente com as regularidades contextuais, desde que feito de forma reflexiva, contribui para o aluno apropriar-se das normas ortográficas; iv) treinos ortográficos que não exigem reflexão são pertinentes apenas como atividades diagnósticas; v) o professor deve conhecer a fundo o sistema ortográfico para poder entender as dificuldades ortográficas de seus alunos; vi) uma ampla formação em Fonética e Fonologia, incluindo modelos baseados no uso, contribui para o entendimento do funcionamento da língua e, consequentemente, para um ensino consciente, menos suscetível a equívocos, muitas vezes reproduzidos nos livros didáticos.

\section{Referências}

BATISTI, E; VIEIRA, M. J. S. O sistema vocálico do português. In: BISOL, L. (Org.). Introdução a estudos de Fonologia do Português Brasileiro. Porto Alegre: EDIPUCRS, 2005. 
BRASIL. Secretaria de Educação Fundamental. Parâmetros curriculares nacionais: terceiro e quarto ciclos. Brasília: MEC/SEF, 2008.

BYBEE, J. The phonology of the lexicon: evidence from lexical diffusion. In: BARLOW, M.; KEMMER, S. (Orgs.). Usage-based models of language. Stanford, 2000. p. 65-85.

BYBEE, J. Phonology and language use. Cambridge University Press, 2001.

BYBEE, J. Word frequency and context of use in the lexical diffusion of phonetically conditioned sound change. Language variation and change. Cambridge University Press, n. 14, p. 261-290, 2002.

BYBEE, J. Mechanisms of change in grammaticization: the role of frequency. In: JOSEF, B. D.; JANDA, J. (Orgs.). The handbook of Historical Linguistic. Oxford: Blackwell, 2003. p. 603-623.

KUSPKE, F. F. É possível adquirir uma língua artificial? O papel comunicativo real na aquisição da linguagem. Travessias, v. 4, n. 2, p. 603620, 2010.

MAGALHÃES, W. R.; CEREJA, T. C. Português Linguagens. São Paulo: Atual, 2009.

MELO, K. L. R. Compreendendo as relações entre consciência gramatical e habilidades de leitura e de escrita: um estudo de intervenção. 2002. Tese (Doutorado em Psicologia) - Universidade Federal de Pernambuco, Recife.

MELO, K. L. R.; REGO, L. L. B. Inovando o ensino da ortografia na sala de aula. Cadernos de Pesquisa, v. 105, p. 110-135, 1998.

REGO, L. L. B.; BUARQUE, L. L. Consciência sintática, consciência fonológica e aquisição de regras ortográficas. Psicologia: reflexão e crítica, Porto Alegre, v. 10, n. 2, p. 199-217, 1997.

SCLIAR-CABRAL, L. Princípios do sistema alfabético do português do Brasil. São Paulo: Contexto, 2003. 